\title{
Flow Duration Hydrograph Analyses for Assessing LID Performance
}

\author{
Michael A. Gregory \\ AECOM, Kitchener, Ontario
}

Received 201406 07, accepted 201412 06, published 20150130.

\begin{abstract}
Low impact development (LID) and other green infrastructure that features onsite retention are now recognized as an integral component of stormwater management. Located as close to the source of runoff generation as possible, one hallmark of LID is a reduction of stormwater runoff volume and pollutant loading to the municipal stormwater management system.

The sizing of LID and other stormwater management facilities across North America largely relies on event based hydrologic modeling methods, which target specific rainfall characteristics. A systems approach to stormwater management requires consideration of both the rainfall stimulus as well as the runoff response, as indicated by impacts to the receiving watercourse or waterbody. Further, continuous simulation offers a greater diagnostic tool for assessing impacts, since it can describe the full range of runoff response characteristics, compared to a limited snapshot view using design storm events.
\end{abstract}

An analysis of continuous simulation results can be used to quantify downstream impacts, particularly through identifying exceedance and deficit durations with respect to threshold values of flow hydrograph ordinates (e.g. flowrate, depth or velocity). In California, a regulatory permitting process has been adopted for identifying potential hydrograph modification (known as hydromodification) based on flow-duration curves that indicate geomorphologic changes due to development.

This paper presents a new methodology that extends California's hydromodification criteria for flow-duration exceedances to encompass a broader range of downstream impacts, and is demonstrated for two case studies that illustrate LID facilities applied under vastly different site conditions.

Keywords: infiltration gallery, rainwater harvesting system, hydromodification, continuous simulation, flow duration analysis.

\section{Systems Approach to Stormwater Management}

Traditional stormwater infrastructure design is focused on peak flow and total volume as the primary runoff response characteristics. As a result, the sizing of stormwater management facilities across North America largely relies on event based hydrologic modeling methods, which target specific rainfall characteristics, namely:

- peak rainfall intensities that affect the conveyance capacity of collection systems (e.g. pipes, ditches and culverts); and

- total rainfall volumes that affect the storage capacity of facilities (e.g. ponds and LID).

While peak flow and total volume are the most important runoff characteristics for design objectives related to flood or erosion hazard mitigation, they are only a subset of the water quantity performance indicators that can be used to assess downstream impacts in a broad watershed management context (Water Environment Federation et al. 2012).

A systems approach to stormwater management requires consideration of the rainfall stimulus as well as the runoff response, as indicated by impacts to receiving watercourses or waterbodies. Even though a stormwater facility may achieve its design objectives for flood control and quality treatment, there are a number of downstream impacts that need to be considered, including:

- geomorphology (flows and sediment loads that shape the watercourse and affect bank and bed stability);

- hydrogeology (baseflows, seepage and groundwater recharge);

- water chemistry (sediment circulation, nutrient cycling and temperature regulation); and

- ecology (aquatic and terrestrial resources that include fisheries, benthic habitat, wildlife, vegetation, and soils that are affected by in-stream velocities, 
water levels, inundation periods, and upland soil water content).

Continuous hydrologic simulation uses a long term observed rainfall record that encompasses a range of historical rainfall events as well as the dry weather periods in between. With continuous simulation, a statistical analysis is conducted on the resulting computed runoff characteristics (e.g. volume, flow depth, velocity and discharge rate). This is very different from event based simulation, where the long term measured rainfall has been replaced by a statistical representation of specific events and it is assumed that the resulting computed runoff is characterized by the same statistics.

Continuous simulation offers a greater diagnostic tool for assessing downstream impacts compared to event based modeling, since it can describe the full range of runoff response characteristics, versus a snapshot of selected individual return period events. As a consequence, in lieu of monitoring, only continuous simulation can be used to assess the long term average performance of a stormwater facility. Further, an analysis of continuous simulation results can be used to quantify downstream impacts, particularly through identifying exceedance or deficit durations with respect to threshold values of runoff hydrograph ordinates.

\section{Flow Duration Analysis}

In California, a regulatory permitting process has been adopted for identifying potential hydrograph modification (known as hydromodification) based on flow duration curves that indicate significant geomorphologic changes due to development. The method requires a hydrograph analysis that tracks the cumulative duration for which individual discharge rates are exceeded under both pre- and post-development conditions at a common point of compliance and over a wide range of flows (Brown and Caldwell 2011).

One hundred equally spaced threshold flows are determined ranging from $10 \%$ of the $2 \mathrm{y}$ return period discharge $\left(0.1 \mathrm{Q}_{2 \mathrm{y}}\right)$ up to the $10 \mathrm{y}$ return period discharge $\left(\mathrm{Q}_{10 \mathrm{y}}\right)$. The cumulative duration (in hours) is computed and the ratio of post- to pre-development flow exceedance durations is calculated for each of the 100 threshold values. According to the hydromodification compliance criteria, any value that exceeds $110 \%$ is identified as a fail, and a passing score of $90 \%$ (i.e. no more than 10 individual fails) must be obtained to achieve compliance.

In this paper, a methodology was developed that extends the California hydromodification criteria for flow duration exceedances, to better align with the overarching objective of mimicking natural hydrology. The California criteria require that post-development durations do not exceed pre-development durations by more than $10 \%$. Stated this way, it is possible to over-control flowrates such that post-development durations are greatly reduced compared to pre-development conditions. Excessive over-control of flows can have a deleterious impact downstream, by depriving receiving watercourses of their base flow or sediment loading, for example.
To truly mimic natural hydrologic conditions, development projects should aim to match the pre-development flow duration curve within a fixed tolerance (e.g. within $\pm 25 \%$ of threshold values) rather than to not exceed threshold values by a fixed tolerance. This applies especially to projects on undeveloped greenfield lands or sites where the pre-development imperviousness is close in magnitude to natural conditions (e.g. within $10 \%)$. However, for redevelopment projects in urban areas where the overall imperviousness is much greater than for natural conditions, it may not be feasible or even possible to return to natural conditions. In California, projects are exempted from the hydromodification criteria in highly urbanized areas where the overall watershed contributing to the receiving watercourse is $>70 \%$ impervious.

\section{Application to Example Properties}

The methodology described above was applied to two LID facilities that were constructed under vastly different site conditions, including:

- the construction of a new infiltration gallery on a site where soils are conducive to infiltration and the pre-development imperviousness was 10\%; and

- the retrofit of an existing rooftop drainage system to allow rainwater harvesting on a site where soils do not allow infiltration and the pre-development imperviousness exceeded $50 \%$.

Computer modeling for both projects was conducted using the stormwater management model SWMM5 (U.S. Environmental Protection Agency 2010). Both facilities were modeled explicitly in the hydraulics module, since the conveyance and storage properties, as well as cistern operations, were too complicated to be represented in the LID module of SWMM5.

Although the two example properties are located in different cities, for instructional purposes the models were applied as if they were located in the same municipality. Meteorological input data were taken from a weather station located within 50 $\mathrm{km}$ (30 mi) of both project sites, including tipping bucket rainfall data for a 22 y period from April 1989 through October 2010. The average annual rainfall $(536 \mathrm{~mm}$ for the months April through October) is well within the range of long term normal values at the nearest long term weather stations (Environment Canada 2012).

Local evaporation time-series data were not available for the complete period of record. As a result, evaporation was represented in a simplified manner using a daily abstraction rate for each calendar month, including the following values during the simulation period:

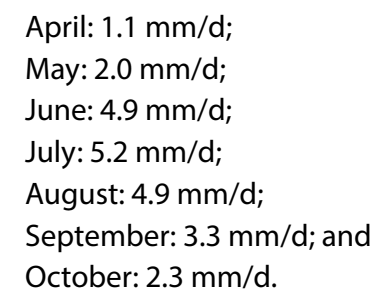


These values represent a total potential evaporation of $725 \mathrm{~mm}$ over the period April through October.

\subsection{Example 1: Infiltration Gallery}

Located in Caledon, Ontario this site discharges into a tributary of the Credit River within the Lake Ontario basin. The servicing design featured a $120 \mathrm{~m}$ (390 ft) storm sewer and swale collection system network throughout the 1.1 ha ( 2.7 acre) site. The design objective was to preserve the natural infiltration features of the underlying soils on site. Runoff is directed to a central infiltration gallery to temporarily store surface runoff for percolation and groundwater recharge (Gregory and Arseneau 2012).

The gallery was constructed in June 2008 and is shown in Figure 1. The gallery is filled with continuous $50 \mathrm{~mm}$ clear stone and covered with native soil material. Stormwater runoff is discharged evenly into the gallery through a manifold perforated pipe system. Runoff exceeding the capacity of the collection system or gallery is designed to discharge via overland sheet flow into the receiving watercourse. Although site development increased the overall imperviousness to $49 \%$ (from $10 \%$ pre-development), continuous simulation results indicated that over $90 \%$ of the average annual runoff generated onsite would be captured and discharged from the gallery into the local groundwater system.

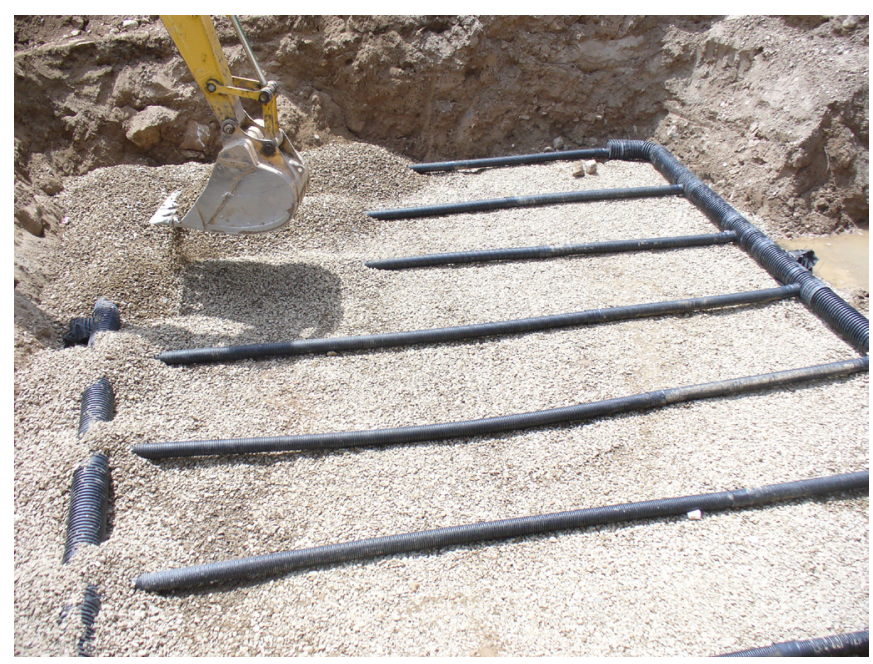

Figure 1 Infiltration gallery construction.

The model was applied to the long term rainfall dataset and a plotting position analysis was applied to the computed peak discharge values at the point of confluence (i.e. surface overflows into the receiving watercourse). A plotting position parameter of 0.41 was used, which is the average value suggested for unbiased plotting positions of Pearson Type 3 probability distributions that characterize extreme hydrologic events (Cunnane 1978). Flow frequency results for various return periods are shown in Table 1, based on an analysis of peak discharge values for all runoff events. Results are tabulated for three development scenarios, namely:
1. Natural conditions: Representative of native hydrology before human intervention. An imperviousness value of $2 \%$ was used to characterize undisturbed surface cover. There were 341 events that produced runoff over the 22 y rainfall period;

2. Pre-development conditions: Representative of the site hydrology (10\% imperviousness, 341 runoff producing events) before the proposed development was undertaken. Differences compared to natural conditions are shown in Table 1; and

3. Post-development conditions: Representative of future conditions with the proposed development (49\% imperviousness, 599 runoff producing events) and stormwater management facilities. Differences compared to natural conditions are also shown.

Table 1 Example 1: Flow frequency analysis results.

\begin{tabular}{|c|c|c|c|c|c|c|c|}
\hline \multirow{3}{*}{$\begin{array}{c}\text { Return } \\
\text { Period }\end{array}$} & \multicolumn{7}{|c|}{ Peak Flow Rate $\left(\mathrm{m}^{3} / \mathrm{s}\right)$} \\
\hline & \multirow{2}{*}{$\begin{array}{c}\begin{array}{c}\text { Natural } \\
\text { Conditions }\end{array} \\
0.337\end{array}$} & \multirow{2}{*}{$\begin{array}{c}\text { Pre-Devel't } \\
\text { Conditions }\end{array}$} & \multicolumn{2}{|c|}{ Difference } & \multirow{2}{*}{$\begin{array}{c}\text { Post-Devel't } \\
\text { Conditions }\end{array}$} & \multicolumn{2}{|c|}{ Difference } \\
\hline & & & 0.038 & $11 \%$ & & 0.330 & $98 \%$ \\
\hline $10 y$ & 0.264 & 0.293 & 0.029 & $11 \%$ & 0.463 & 0.199 & $75 \%$ \\
\hline $5 y$ & 0.076 & 0.086 & 0.010 & $13 \%$ & 0.094 & 0.018 & $24 \%$ \\
\hline $2 y$ & 0.015 & 0.022 & 0.007 & $46 \%$ & 0.011 & -0.004 & $-27 \%$ \\
\hline $1 y$ & 0.004 & 0.012 & 0.008 & $215 \%$ & 0.008 & 0.004 & $110 \%$ \\
\hline 6 month & 0.003 & 0.009 & 0.006 & $200 \%$ & 0.006 & 0.003 & $100 \%$ \\
\hline 3 month & 0.002 & 0.006 & 0.004 & $200 \%$ & 0.003 & 0.001 & $50 \%$ \\
\hline
\end{tabular}

Figure 2 plots the flow frequency curves for the three development scenarios, highlighting the range below $\mathrm{Q}_{10 \mathrm{y}}$. Despite development that increases the site imperviousness nearly fivefold, the infiltration gallery yields lower peak discharge to the receiving watercourse than pre-development conditions up to an average recurrence interval of $\sim 4 \mathrm{y}$. Beyond a $4 \mathrm{y}$ return period, peak discharge exceeded pre-development conditions for only $1 \%$ of the runoff producing rainfall events (i.e. 6 of 599).

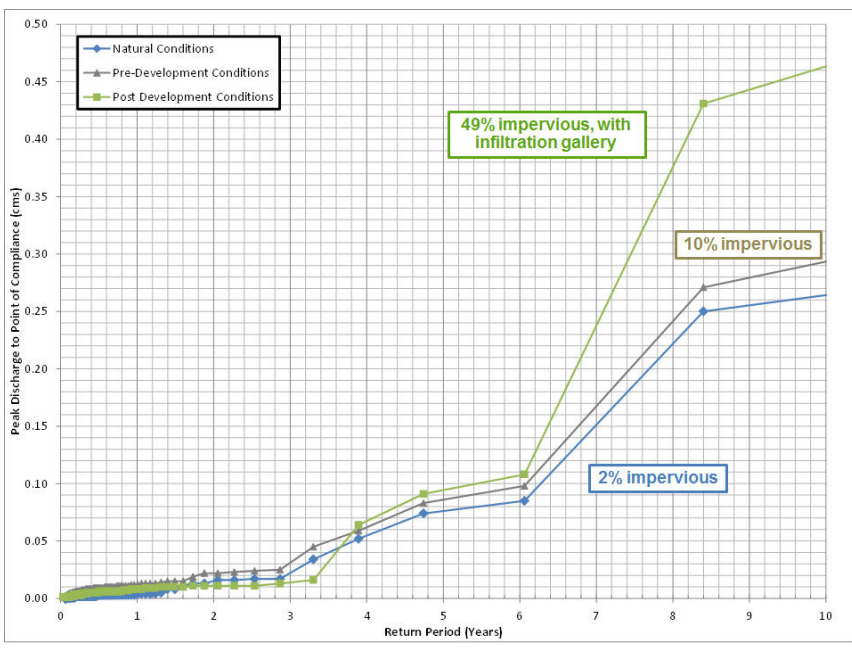

Figure 2 Infiltration gallery flow frequency analysis. 
Model results were processed by tracking the cumulative duration for a range of threshold flows at the corresponding point of compliance. Flow exceedance duration curves are plotted in Figure 3.

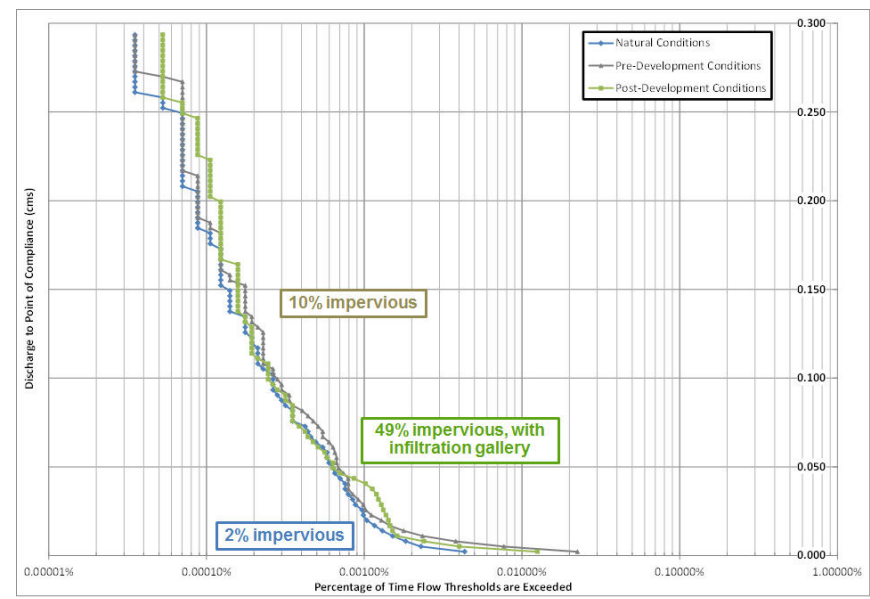

Figure 3 Infiltration gallery flow duration analysis.

The duration analysis plotted in Figure 3 required processing of the complete set of flow hydrograph ordinates over the period from April 1989 through October 2010.

The accuracy of the analysis improves with a higher resolution in the output timestep. With a computational timestep of $1 \mathrm{~s}$, the ideal output resolution would be in the order of $30 \mathrm{~s}$ to $1 \mathrm{~min}$; however, the resulting file sizes led to difficulty in processing the output data. A 2 min output timestep was chosen for this analysis, resulting in a flow hydrograph with 5677920 data points.

The cumulative duration that flow hydrograph values exceeded each of the 100 equally spaced threshold values was determined, from $0.1 \mathrm{Q}_{2 y}$ up to $\mathrm{Q}_{10 \mathrm{y}^{\prime}}$ under pre-development conditions (i.e. $0.002 \mathrm{~m}^{3} / \mathrm{s}$ and $0.293 \mathrm{~m}^{3} / \mathrm{s}$ respectively). The duration was expressed as a percentage of the $22 \mathrm{y}$ simulation period and plotted on the logarithmic $x$-axis of Figure 3.

\subsection{Example 2: Rainwater Harvesting System}

Located in Waterloo, Ontario this site discharges into a tributary of the Grand River within the Lake Erie basin. The system was designed to collect runoff from rooftops that could be drained by gravity into the cistern. The cistern was installed as an interconnected series of eight pre-cast modular units in November 2013. Figure 4 shows the top half of one of the units being lowered into place.

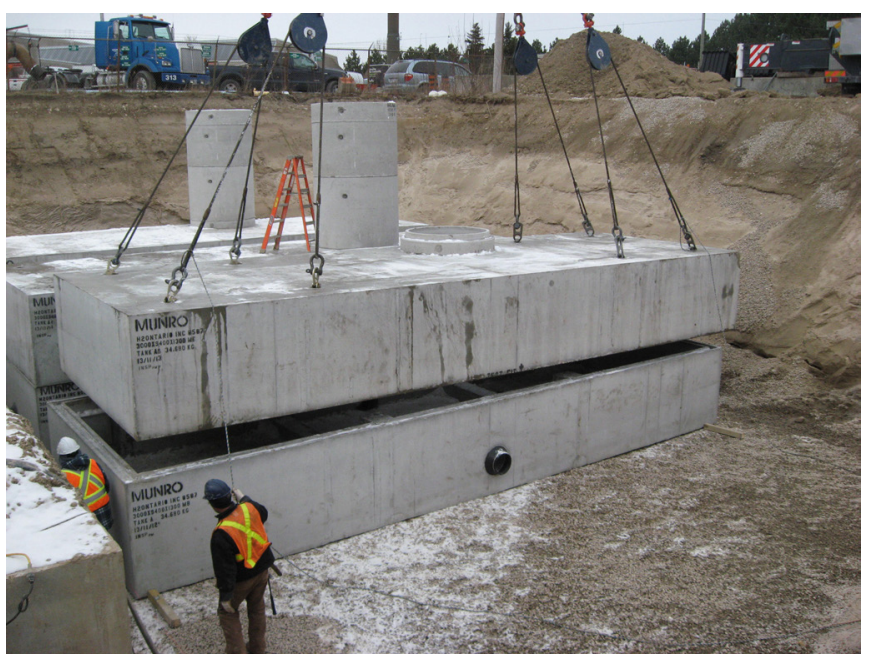

Figure 4 Cistern construction.

Water demands were quantified throughout the 5.8 ha (14.3 acre) site, and included multiple uses in the main building, plant watering in the greenhouse, exterior vehicle and equipment cleaning at the washbay, and offsite landscaping and street sweeping uses. This was a retrofit project and the overall site imperviousness did not change from its $61 \%$ pre-development value. For an average year of rainfall (non-snowmelt period from April 1 through October 31), it was determined that a cistern volume of $450 \mathrm{~m}^{3}$ (118400 gal) could supply $83 \%$ of the total demand for harvested rainfall.

Flow frequency results for various return periods are shown in Table 2, based on an analysis of peak discharge values for all runoff events in the corresponding development scenario.

Table 2 Example 2: Flow frequency analysis results.

\begin{tabular}{cccccccc}
\hline & \multicolumn{7}{c}{ Peak Flow Rate (m $\left.{ }^{3} / \mathrm{s}\right)$} \\
Return & Natural & $\begin{array}{c}\text { Pre-Devel't } \\
\text { Period }\end{array}$ & Conditions & Conditions & Difference & $\begin{array}{c}\text { Post-Devel't } \\
\text { Conditions }\end{array}$ & Difference \\
\hline $25 y$ & 0.186 & 1.478 & 1.292 & $693 \%$ & 1.498 & 1.312 & $704 \%$ \\
$10 y$ & 0.125 & 1.349 & 1.224 & $978 \%$ & 1.413 & 1.288 & $1030 \%$ \\
$5 y$ & 0.024 & 1.227 & 1.203 & $5020 \%$ & 1.198 & 1.174 & $4901 \%$ \\
$2 y$ & 0.008 & 0.855 & 0.847 & $11025 \%$ & 0.755 & 0.747 & $9718 \%$ \\
$1 y$ & 0.006 & 0.657 & 0.651 & $10851 \%$ & 0.543 & 0.537 & $8944 \%$ \\
6 month & 0.004 & 0.422 & 0.418 & $10450 \%$ & 0.325 & 0.321 & $8032 \%$ \\
3 month & 0.002 & 0.281 & 0.278 & $11203 \%$ & 0.210 & 0.208 & $8370 \%$ \\
\hline
\end{tabular}

Figure 5 plots the flow frequency curves for the three development scenarios, highlighting the range below $Q_{10 y}$. As a retrofit project, there is no change to the pre-development site imperviousness of $61 \%$, and the rainwater harvesting system yields lower peak discharge to the receiving watercourse than pre-development conditions up to an average recurrence interval of $\sim 7 \mathrm{y}$. By comparing results to natural hydrology (at $2 \% \mathrm{im}-$ perviousness), the disturbed nature of the pre-development site conditions is evident in Figure 5. 


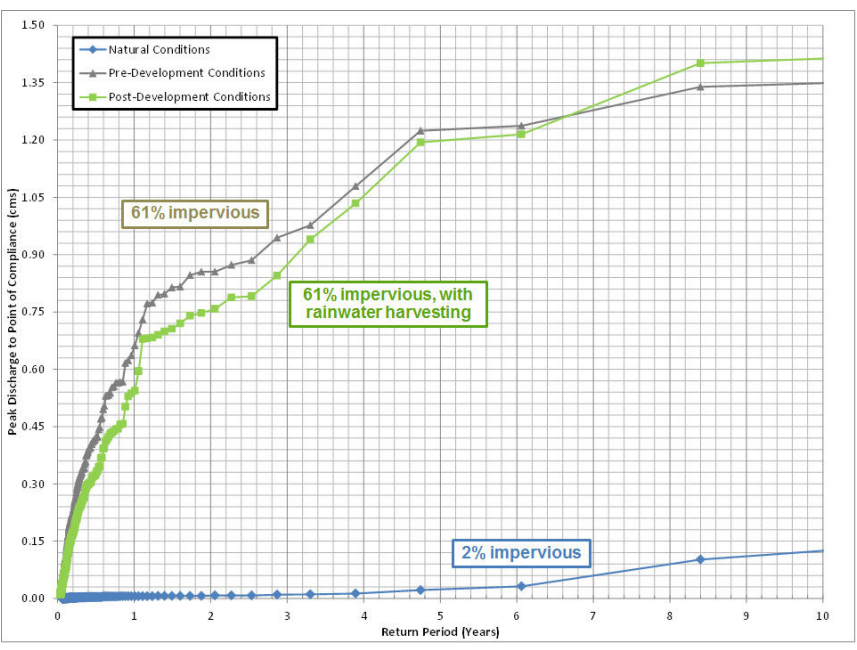

Figure 5 Rainwater harvesting system flow frequency analysis.

The resulting flow exceedance duration curves are plotted in Figure 6, based on a hydrograph analysis that also used a 2 min output timestep. The cumulative duration for which flow hydrograph values exceeded each of the 100 equally spaced threshold values was determined, from $0.1 \mathrm{Q}_{2 y}$ up to $\mathrm{Q}_{10 \mathrm{y}^{\prime}}$ under pre-development conditions (i.e. $0.086 \mathrm{~m}^{3} / \mathrm{s}$ and $1.349 \mathrm{~m}^{3} / \mathrm{s}$ respectively). The disturbed nature of site conditions prior to construction is also evident in Figure 6, as the majority of flows for natural hydrologic conditions fall below the $0.1 Q_{2 y}$ value and therefore are not plotted.

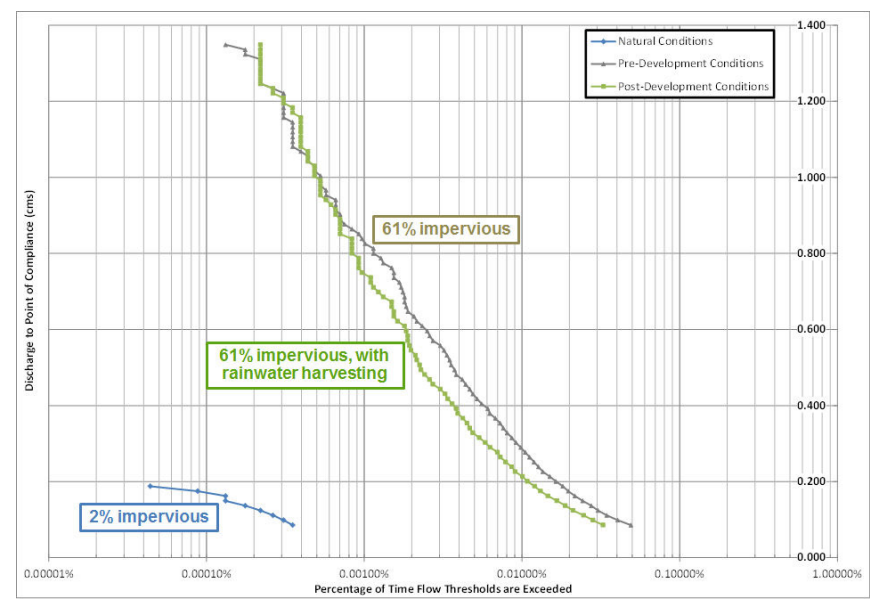

Figure 6 Rainwater harvesting system flow duration analysis.

\subsection{Discussion}

A comparison of the flow frequency and duration plots reveals the disparity in runoff responses between the two project examples, particularly with respect to natural hydrologic conditions. With the infiltration gallery, not only does the post-development flow duration curve closely match the pre-development curve, but it also appears to mimic natural conditions. With the rainwater harvesting system, given the greatly disturbed pre-development conditions, it is doubtful that any remedial measures will be able to mimic native hydrology.

As a result, an assessment of hydraulic performance that includes flow duration indicators should reflect differences in pre-development runoff response characteristics. That is, separate criteria should be applied to sites depending on the difference between pre-development and natural imperviousness. It is suggested that a reasonable breakpoint is in the order of $10 \%$ to $20 \%$, such that it is feasible that stormwater management facilities can be designed to mimic natural hydrologic conditions. In such cases, the level of flow duration control could be indicated by how closely the pre-development flow duration curve remains within a fixed tolerance of threshold values compared to natural conditions.

Table 3 shows how the suggested flow duration criteria would be applied. For the first example, the pre-development imperviousness is within $10 \%$ of natural conditions and the pass criteria shown are used to quantify how closely flow durations are within a $\pm 25 \%$ flow duration tolerance. In the criteria, $X$ equals the ratio of post- to pre-development flow exceedance durations, computed for each threshold value. The control level reflects the number of flow threshold values that achieve the pass criteria. For example, with the infiltration gallery the post-development flow duration curve is within $\pm 25 \%$ of the pre-development curve for 72 of the 100 threshold values shown in Figure 3.

Table 3 Flow duration control summary.

\begin{tabular}{lcccc}
\hline \multicolumn{1}{c}{ Project Example } & $\begin{array}{c}\text { Point of } \\
\text { Compliance }\end{array}$ & $\begin{array}{c}\Delta_{\text {Imperviousness }} \\
\text { Pre-Devel't: Natural }\end{array}$ & Pass Criteria & $\begin{array}{c}\text { Control } \\
\text { Level }\end{array}$ \\
\hline 1: Infiltration Gallery & Shaws Creek & $8 \%$ & $0.75 \leq \mathrm{X} \leq 1.25$ & $72 \%$ \\
2: Rainwater Harvesting & existing pond & $59 \%$ & $\mathrm{X} \leq 1.00$ & $87 \%$ \\
\hline
\end{tabular}

For disturbed sites, where it is not reasonable to expect the facility design to mimic natural conditions, it is sufficient to evaluate hydraulic performance based on simply reducing flow durations below pre-development conditions. This is reflected in the bottom row of Table 3. For example, with the rainwater harvesting system the post-development flow duration curve is less than the pre-development curve for 87 of the 100 threshold values shown in Figure 6.

\section{Conclusions}

By adopting LID and reuse as source controls in critical neighbourhoods, municipalities can take great steps towards meeting their stormwater management and water quality objectives, as well as promoting green infrastructure principles in a highly visible, innovative and cost effective manner. Traditional design objectives for sizing stormwater management facilities across North America rely on the use of event based hydrology, which is limited in its ability to assess potential impairment to downstream receiving watercourses. 
This paper presents a new methodology using continuous hydrologic simulation that can complement facility design or hydraulic performance evaluations of existing systems by quantifying the level of flow duration control compared to pre-development conditions. Flow duration compliance criteria were developed that distinguish sites with vastly different runoff response characteristics, allowing a range of applications from the new development of greenfield lands to retrofit projects in areas that have already been developed.

The methodology was demonstrated for two project examples that bracket a wide range of LID installations, including:

- the construction of a new infiltration gallery located on a site where soils are conducive to infiltration; and

the retrofit of an existing rooftop drainage system for consumptive use of stormwater on a site where soils do not allow infiltration.

\section{References}

Brown and Caldwell, Inc. 2011. San Diego County-Wide Hydromodification Plan. San Diego, CA: Project Clean Water. Accessible from http://www.projectcleanwater.org.

Cunnane, C. 1978. “Unbiased Plotting Positions: A Review." Journal of Hydrology 37:205-22.
Environment Canada. 2012. Canadian Climate Normals 1981-2010 Station Data. Ottawa: National Climate Data and Information Archive, Meteorological Service of Canada. http:// climate.weather.gc.ca.

Gregory, M. and D. Arseneau. 2012. "Design, Construction and Hydraulic Performance Assessment of an Infiltration Gallery." Journal of Water Management Modeling R245-10. doi: 10.14796/JWMM.R245-10.

U.S. Environmental Protection Agency. 2010. Storm Water Management Model User's Manual, Version 5.0. Cincinnati, $\mathrm{OH}$ : National Risk Management Research Laboratory, Office of Research and Development. EPA/600/R-05/040. http:// www.epa.gov.

Water Environment Federation, American Society of Civil Engineers and Environmental \& Water Resources Institute. 2012. Design of Urban Stormwater Controls, WEF Manual of Practice No. 23, ASCE/EWRI Manual No. 87. Alexandria, VA: Water Environment Federation. ISBN 978-0-07-170444-1. 